\title{
ASSOCIATIONS BETWEEN FUNCTIONAL MILESTONES AND PSYCHIATRIC ADMISSIONS IN AN URBAN AREA: UTILITY OF A CLUSTER-ANALYTICAL APPROACH
}

\author{
Cristiana Montemagni ${ }^{1}$, Tiziana Frieri ${ }^{1}$, Vincenzo Villari ${ }^{2}$ \& Paola Rocca ${ }^{1}$ \\ ${ }^{I}$ Department of Neuroscience, University of Turin, Struttura Semplice di Coordinamento a Valenza Dipartimentale (SSD), \\ Department of Neuroscience and Mental Health A.O.U. Città della Salute e della Scienza di Torino, Torino, Italy \\ ${ }^{2}$ Department of Neuroscience and Mental Health, SC Psychiatry SPDC, A.O.U. Città della Salute e della Scienza,
} Turin, Italy

received: 27.11.2017;

revised: 9.1.2018;

accepted: 21.2 .2018

\section{SUMMARY}

Background: The purpose of the study was to identify homogenous subgroups, based upon achievement of two functional milestones (marriage and employment) and Global Assessment of Functioning (GAF) score in a sample of 848 acute patients admitted to the Psychiatric Emergency Service (PES) of the Città della Salute e della Scienza di Torino, during a 24-months period.

Subjects and methods: A two-step cluster-analysis, using GAF total score and the achievements in the two milestones as input data was performed. In order to examine whether the identified subgroups differed in external variables that were not included in the clustering process, and consequently to validate the found functional profiles, chi-square tests for categorical variables and analyses of variance (ANOVA) for continuous variables were performed.

Results: Five clusters were found. Employed patients (Clusters 4 and 5) had more years of education, less illness chronicity (shorter duration of illness and lower proportion of previous voluntary hospitalizations), lower use of mental health resources in the last year yet higher treatment adherence, larger network size, and higher ordinary discharge. Married inpatients (Clusters 3 and 5) had lower frequencies of substance abuse.

Conclusions: The remarkably high rate of unemployment in this inpatients' sample, and the evidence of associations between unemployment and poorer functioning, argue for further research and development of evidence-based supported employment programs, that put forth diligent effort in helping people obtain work quickly and sustain; they may also help to reduce health care service use among that clientele.

Key words: functional milestones - cluster analysis - marriage - Global Assessment of Functioning - severe mental illnesses

$$
* * * * *
$$

\section{INTRODUCTION}

Severe mental illnesses are responsible for a significant proportion of burden of diseases. Their disability is pervasive affecting social, vocational, and, sometimes, residential domains (Harvey et al. 2011). Impairments in these domains are evidenced by reductions in achieving functional milestones common in general population, such as independent living, employment, and marriage or a long-term relationship (Leung et al. 2008).

Furthermore, people with severe mental illnesses are heavy users of health services (Herman \& Mowbray 1991), however they are more likely to have higher rates of non-attendance at follow-up visits, and lack of active follow-up system, particularly in the country's urban areas that has resulted in the revolving door phenomenon of re-hospitalizations (Alonso Suarez et al. 2011, Dixon \& Schwarz 2014).

Moreover, severe psychiatric illnesses are phasic (Murphy et al. 2012). After initial treatment, people with schizophrenia or other similar disorders usually experience long periods of relative stability. Relapses or crises can, however, occur: some crises are short term and can be resolved in the psychiatric emergency room within a relatively brief period of time. Other crises require a longer period of time for stabilization, usually in a general hospital inpatient setting (Unick et al. 2011). Most contemporary hospitalizations are extremely brief. Several reasons have been reported contributing to the admission to a psychiatric inpatient facility: presence of a severe mental disorder, risk to self or others, need of diagnostic assessment, need of medical treatment, revision of the medication regime, lack of self-care and need of respite for the patient or his/her carers (Bowers 2005).

However, despite its crucial importance, the supporting evidence of the role of social functioning on psychiatric admission in severe psychiatric disorders is sparse. Moreover, no studies have yet investigated the role of two functional milestones on psychiatric hospitalization, i.e., it is not yet established whether the achievement of a specific functional milestone involves different outcomes as regards hospitalization.

Our a priori hypothesis was that patients with severe mental illnesses who have achieved one or more functional milestones would react to crises or relapses differently, representing distinct patient subgroups, with different characteristics and needs, even when they were hospitalized. Thus, the aims of the present study were as follows: 1) to identify homogenous and specific subgroups of inpatients with similar characteristics and 
needs, based upon achievement of two functional milestones (marriage and employment) and GAF score; 2 ) to validate these profiles by identifying differential associations with sociodemographic, anamnestic, and clinical characteristics.

This study was conducted in a large cohort of inpatients with severe mental illnesses representative of the usual setting and modality of care of a psychiatric emergency service (PES) in a geographically well-defined catchment area in Italy. Italian psychiatric services are public, based on catchment areas and are available to everyone. Almost all patients with psychiatric disorders are primarily referred to the psychiatric department of the local hospital for their catchment area. This allowed us to study a sample of all patients consecutively admitted within a specified time period from one catchment area. The results from this study may be useful in informing further service development.

\section{SUBJECTS AND METHODS}

\section{Patient population}

The present study was conducted in the period between January 2007 and December 2008 in the PES, Department of Neuroscience and Mental Health, A.O. Città della Salute e della Scienza di Torino - Presidio Molinette, Turin. It is part of the first hospital in Italy concerning the size and the indices for complexity of care. Due to the local organization of mental health that has divided the urban area of the city into zones, this PES is the only acute inpatient psychiatric facility of reference for the population of the corresponding zone. It provides emergency care for a population of approximately 120.000 inhabitants with a total of almost 450 admissions every year.

Patients admitted in the ward were identified by our researcher team (T.F., C.M.) and approached within 72 $\mathrm{h}$ of admission, through ongoing contacts with PES clinical staff. The interviewing psychiatrists were never members of the patients' treating team and were not involved in the clinical activity of the emergency department during the study period.

All consecutive patients in the 18-65 years age group were asked to participate if 1) they had comprehension skills sufficient to understand clinicians' questions and verbal information in order to avoid possible distortion in responding to assessment questions; 2) they were able to understand and speak the Italian language.

All patients underwent clinical examination. Diagnoses, formulated by the treating consultant psychiatrist, were confirmed using the Structured Clinical Interview for DSM-IV disorders (SCID-I and SCID-II) (First et al. 1997a,b). All available psychiatric diagnoses were examined and classified according to the following four main categories: Non Affective Psychoses (P), Depressive Disorders (DD), Mania (M), Personality Disorders (PD). Subjects with a current disorder other than those above-mentioned were excluded.
To avoid duplication, only data for the first hospitalization of patients who had multiple hospitalizations were included in this analysis.

The protocol was approved by a Local Research Ethics Committee (LREC) (CEI 185). Because data collection was integrated as part of the regular diagnostic assessment procedure and of the quality check processes that don't influence therapeutic decisions or outcomes and because the data were analysed anonymously, the LREC agreed that informed consent was not required. All personally sensitive information contained in the database used for this study was previously de-identified according to the Italian legislation. The study was carried out in accordance with the Declaration of Helsinki (with amendments) and Good Clinical Practice.

\section{Psychiatric assessment}

Upon patients' arrival at the PES a semistructured interview was filled out. The data were extracted from medical and nursing records and medication schedules of patients who were admitted in the PES during the study period. Further, missing data were collected from the patient after the remission of the acute episode or obtained by archival sources as well as detailed reports from community mental health teams and primary care physicians.

Clinical ratings included the Clinical Global Impression - Severity (CGI-S) (Guy 1976) and the Brief Psychiatric Rating Scale (BPRS) (Overall \& Gorham 1962).

To evaluate the social network, participants estimated the number of persons outside of their household, with whom they had regular and meaningful contact. Also, the number of persons (partners included, if present) who they experienced as being emotionally or materially supportive to them was documented. To quantify the global functioning of patients, we used the Global Assessment of Functioning scale (GAF) (Jones et al. 1995). For the purpose of our study, raters was instructed to use the GAF to measure only psychosocial functioning in the month before rating (Altshuler et al. 2002, Martinez-Aran et al. 2004, Martinez-Aran et al. 2007).

\section{Functional milestones achievements}

Functional milestones were defined in line with Harvey et al. (2012) and included social outcomes such as ever being married, currently or previously engaged, which we categorized as current or former relationship vs. none. Vocational outcome was categorized as employed vs. not employed. We dichotomized these outcome measures.

We collected information from patients, informants, and medical records on the achievement of functional milestones. In cases of uncertainty, a consensus was obtained through discussion with the principal investigator (P.R.) and the interviewer 
Table 1. Cluster characteristics in observed variables and differences among clusters-categorical measures (interview $\underline{\text { sample}=848)}$

\begin{tabular}{|c|c|c|c|c|c|c|c|}
\hline $\begin{array}{l}\text { Categorical } \\
\text { variables N (\%) }\end{array}$ & $\begin{array}{c}\text { Cluster } 1 \\
\mathrm{UM} / \mathrm{UE} \\
\mathrm{GAF}=37.1 \\
(\mathrm{~N}=287)\end{array}$ & $\begin{array}{l}\text { Cluster } 2 \\
\mathrm{UM} / \mathrm{UE} \\
\mathrm{GAF}=54.0 \\
(\mathrm{~N}=159)\end{array}$ & $\begin{array}{c}\text { Cluster } 3 \\
\mathrm{M} / \mathrm{UE} \\
\mathrm{GAF}=44.5 \\
(\mathrm{~N}=152)\end{array}$ & $\begin{array}{c}\text { Cluster } 4 \\
\mathrm{UM} / \mathrm{E} \\
\mathrm{GAF}=48.3 \\
(\mathrm{~N}=165)\end{array}$ & $\begin{array}{c}\text { Cluster } 5 \\
\mathrm{M} / \mathrm{E} \\
\mathrm{GAF}=49.1 \\
(\mathrm{~N}=85)\end{array}$ & $\chi^{2}$ (d.f.) & $\begin{array}{l}\text { Significant } \\
\text { comparisons }\end{array}$ \\
\hline Sex, females & $127(44.3)$ & $92(57.9)$ & $102(67.1)$ & $84(50.9)$ & $37(43.5)$ & $25.510(4)$ & $3>1,4,5$ \\
\hline $\begin{array}{l}\text { Diagnoses } \\
\text { Non affective psychoses } \\
\text { Depressive disorders } \\
\text { Mania } \\
\text { Personality disorders }\end{array}$ & $\begin{array}{l}176(61.3) \\
29(10.1) \\
30(10.5) \\
52(18.1)\end{array}$ & $\begin{array}{c}49(30.8) \\
46(28.9) \\
14(8.8) \\
50(31.4)\end{array}$ & $\begin{array}{l}48(31.6) \\
52(34.2) \\
33(21.7) \\
19(12.5)\end{array}$ & $\begin{array}{l}57(34.5) \\
50(30.3) \\
30(18.2) \\
28(17.0)\end{array}$ & $\begin{array}{l}23(27.1) \\
36(42.4) \\
17(20.0) \\
9(10.6)\end{array}$ & $120.459(12)$ & $\begin{array}{c}1>2,3,4,5 \\
1<2,3,4,5 \\
1,2<3 \\
2>1,3,4,5\end{array}$ \\
\hline $\begin{array}{l}\text { Past vol. hospitalizations } \\
\text { Past invol. hospitalizations }\end{array}$ & $\begin{array}{l}242(84.3) \\
99(34.5)\end{array}$ & $\begin{array}{l}115(72.3) \\
37(23.3)\end{array}$ & $\begin{array}{l}110(72.3) \\
23(15.1)\end{array}$ & $\begin{array}{l}73(44.2) \\
26(15.8)\end{array}$ & $\begin{array}{c}42(49.4) \\
3(3.5)\end{array}$ & $\begin{array}{l}62.696(4) \\
50.790(4)\end{array}$ & $\begin{array}{l}1>3,4,5 \\
5<3,4\end{array}$ \\
\hline $\begin{array}{l}\text { Mental health services } \\
\text { engagement }\end{array}$ & $254(88.5)$ & $129(81.1)$ & $118(77.6)$ & $100(60.6)$ & $49(57.6)$ & $65.273(4)$ & $1>3,4,5 ; 2,3>4,5$ \\
\hline Medication adherence & $88(44.2)$ & $83(52.2)$ & $77(50.6)$ & $123(74.5)$ & $69(81.2)$ & $115.032(4)$ & $2,3<4,5 ; 1<2,3,4,5$ \\
\hline Substance abuse & $96(33.4)$ & $51(32.1)$ & $30(19.7)$ & $57(34.5)$ & $13(15.3)$ & $19.985(4)$ & $1>3,5 ; 4>3,5$ \\
\hline Self-injuries & $20(7.0)$ & $11(6.9)$ & $15(9.9)$ & $22(13.3)$ & $19(22.4)$ & $20.595(4)$ & $5>1,2$ \\
\hline $\begin{array}{l}\text { Network size } \\
\quad \text { Small }(0-1) \\
\text { Medium }(2-5) \\
\text { Large }(>6)\end{array}$ & $\begin{array}{l}120(41.8) \\
115(40.1) \\
52(18.1)\end{array}$ & $\begin{array}{l}33(20.7) \\
94(59.1) \\
32(20.1)\end{array}$ & $\begin{array}{l}27(17.8) \\
103(67.8) \\
21(14.0)\end{array}$ & $\begin{array}{l}12(7.3) \\
74(44.8) \\
79(47.9)\end{array}$ & $\begin{array}{c}4(4.7) \\
34(40.0) \\
47(55.3)\end{array}$ & $\begin{array}{l}98.916(8) \\
40.874(8) \\
99.142(8)\end{array}$ & $\begin{array}{c}1>2,3,4,5 ; 2,3>4,5 \\
1>2,3 ; 3>4,5 \\
1<4,5 ; 2,3<4,5\end{array}$ \\
\hline $\begin{array}{l}\text { Confident/supportive person } \\
\text { None } \\
>1 \text { person } \\
\geq 2 \text { persons }\end{array}$ & $\begin{array}{l}114(39.7) \\
131(45.6) \\
42(14.6)\end{array}$ & $\begin{array}{l}33(20.7) \\
88(55.3) \\
38(23.9)\end{array}$ & $\begin{array}{l}27(17.8) \\
104(68.4) \\
21(13.8)\end{array}$ & $\begin{array}{l}12(7.3) \\
74(44.8) \\
79(47.9)\end{array}$ & $\begin{array}{c}4(4.7) \\
34(40.0) \\
47(55.3)\end{array}$ & $\begin{array}{c}115.649(8) \\
7.873(8) \\
82.702(8)\end{array}$ & $\begin{array}{c}1>2,3,4,5 ; 2>4,5 \\
1<3,4,5 ; 2<4,5\end{array}$ \\
\hline Ordinary discharge & $115(40.1)$ & $89(56.0)$ & $85(55.9)$ & $118(71.5)$ & $64(75.3)$ & $17.453(4)$ & $1<2,3,4,5 ; 2,3<4,5$ \\
\hline
\end{tabular}

Table 2. Cluster characteristics in observed variables and differences among clusters-continuous measures (interview sample=848)

\begin{tabular}{|c|c|c|c|c|c|c|c|}
\hline $\begin{array}{l}\text { Continuous } \\
\text { variables } \\
\text { mean (SD) }\end{array}$ & $\begin{array}{c}\text { Cluster } 1 \\
\mathrm{UM} / \mathrm{UE} \\
\mathrm{GAF}=37.1 \\
(\mathrm{~N}=287)\end{array}$ & $\begin{array}{c}\text { Cluster } 2 \\
\mathrm{UM} / \mathrm{UE} \\
\mathrm{GAF}=54.0 \\
(\mathrm{~N}=159)\end{array}$ & $\begin{array}{c}\text { Cluster } 3 \\
\mathrm{M} / \mathrm{UE} \\
\mathrm{GAF}=44.5 \\
(\mathrm{~N}=152)\end{array}$ & $\begin{array}{c}\text { Cluster } 4 \\
\mathrm{UM} / \mathrm{E} \\
\mathrm{GAF}=48.3 \\
(\mathrm{~N}=165) \\
\end{array}$ & $\begin{array}{c}\text { Cluster } 5 \\
\mathrm{M} / \mathrm{E} \\
\mathrm{GAF}=49.1 \\
(\mathrm{~N}=85)\end{array}$ & $\begin{array}{l}\text { ANOVA F } \\
\text { (d.f.) }\end{array}$ & $\begin{array}{l}\text { Significant } \\
\text { comparisons }\end{array}$ \\
\hline Age & $41.1(13.9)$ & $43.9(15.1)$ & $52.0(15.0)$ & $37.2(10.3)$ & $43.7(9.48)$ & $26.698(4)$ & $4<1,2,3,5 ; 3>$ \\
\hline Years of education & $9.28(2.99)$ & $9.42(3.31)$ & $8.51(3.68)$ & $10.5(3.34)$ & $10.7(3.38)$ & $9.062(4)$ & $4,5>1,2,3$ \\
\hline Duration of illness & $11.5(8.17)$ & $9.16(7.59)$ & $9.65(9.07)$ & $5.91(6.64)$ & $5.03(6.69)$ & $19.328(4)$ & $4,5<1,2,3 ; 1>2$ \\
\hline BPRS & $53.6(11.6)$ & $42.0(10.7)$ & $47.0(13.0)$ & $44.6(12.9)$ & $43.3(10.7)$ & $32.704(4)$ & $1>2,3,4,5 ; 3>2$ \\
\hline CGI-S & $5.68(0.88)$ & $4.35(0.83)$ & $4.88(0.93)$ & $4.73(0.85)$ & $4.55(0.95)$ & $73.896(4)$ & $1>2,3,4,5 ; 2<3,4$ \\
\hline
\end{tabular}

Abbreviations: $\mathrm{UM}=$ unmarried; $\mathrm{UE}=$ unemployed; $\mathrm{GAF}=$ Global Assessment of Functioning; $\mathrm{BPRS}=$ Brief Psychiatric Rating Scale; CGI-S= Clinical Global Impression - Severity.

All assessments were performed by the same welltrained experienced interviewing psychiatrists (T.F., C.M.) who were blinded to the diagnosis, psychiatric history, and pharmacological treatment. In an attempt to reduce inter-rater variability, raters were trained to administer the psychometric tools according to common standards. Efforts were made to maintain inter-rater reliability across the entire study period, including careful calibration and standardization procedures and regular, in-depth review of a sample of interviews with the lead author.

\section{Statistical analysis}

Analyses were planned in 2 stages.

In stage 1, to identify patient subgroups, a cluster-analytic approach was chosen (Clatworthy et al. 2005). To minimize the dependence of the solution on the method chosen, we decided to perform a two-step cluster analysis (TSCA) (Bischof et al. 2003, Theodoritis \& Koutrumbas 1999, Chiu et al. 2001), using GAF total score and the achievements in the two milestones as input data. TSCA is a procedure designed to reveal grou- 
pings (i.e., clusters) within a dataset that would not otherwise be apparent. The algorithm employed has several desirable features that differentiate it from traditional cluster techniques. These include: analysing large data files, handling of both categorical and continuous variables as well as automatic selection of the number of clusters. A computer algorithm inductively determines the number of clusters based on the Log-likelihood distance and Schwarz's Bayesian Criterion (BIC) for clustering."

In stage 2, in order to examine whether the identified subgroups differed in external variables that were not included in the clustering process, and consequently to validate the found functional profiles, we performed chi-square tests for categorical variables an analyses of variance (ANOVA) for continuous variables.

In the case of a significant $\mathrm{F}$ from one or more ANOVAs, post-hoc pair-wise comparisons were performed using Bonferroni's test. In the case of categorical data, Fisher's exact test was used to compute the six pairwise comparisons between the clusters. In order to control for Type 1 error, alpha was set at $0.005(0.05 / 10)$.

We did not control for covariates as we investigated natural groups instead of experimental groups (Miller \& Chapman 2001, Santone et al. 2008, Lysaker et al. 2009).

Statistical analyses were performed using the software Statistical Package for the Social Sciences, SPSS, version 21 for Windows (SPSS, Chicago, IL, USA). Data are presented as means \pm standard deviations (SD) or percentages $(\%)$, unless stated otherwise.

\section{RESULTS}

\section{Subject characteristics}

During the 24-months period of inclusion, 951 acute patients were admitted in the PES, of those 894 were eligible for the study. Fifty-seven patients were not included due to languages barriers as they if they had not comprehension skills sufficient to understand clinicians' questions and verbal information or they were able to understand and speak the Italian language. The final sample consisted of 848 inpatients, because of 24 patients were discharged before the assessment and 22 had missing data.

The general socio-demographic characteristics of the whole sample have been recently reported (Montemagni et al. 2012, Frieri et al. 2013, 2014).

\section{Cluster description}

Based on the achievement of two functional milestones and on the GAF score, the cluster analysis revealed five distinct patient clusters: 1) Cluster 1, accounting for $33.8 \%$, characterized by currently unemployed and unmarried inpatients, with a GAF score of 37.1(SD $\pm 6.025)$; 2) Cluster 2, accounting for $18.7 \%$, characterized by currently unemployed and unmarried inpa- tients, with a GAF score 54.0( $\mathrm{SD} \pm 6.359)$; 3) Cluster 3, accounting for $17.9 \%$ of the whole sample, characterized by currently married and unemployed inpatients, with a baseline GAF score of $44.5(\mathrm{SD} \pm 10.530)$; 4) Cluster 4 , accounting for $19.4 \%$, characterized by currently employed and unmarried inpatients, with a GAF score of 48.3 ( $\mathrm{SD} \pm 9.548)$; 5) Cluster 5, accounting for $10.0 \%$, characterized by currently employed and married inpatients, with a GAF score of 49.1 ( $\mathrm{SD} \pm 8.331)$.

The Silhouette value of cohesion (more than 0.50) shows that a reasonable structure has been found.

Patient characteristics by level of functioning and significant difference between the clusters are reported in Tables 1 and 2.

As revealed in Tables 1 and 2 Cluster 1 contained more inpatients with Non Affective Psychoses and fewer patients with Depressive Disorders. Moreover, Cluster 1 contained more inpatients with past voluntary hospitalizations and fewer inpatients with ordinary discharge. The BPRS and CGI-S overall scores were significantly higher in Cluster 1 as compared with the other Clusters $(\mathrm{p}<0.0001)$ at admission. Cluster 1 had an average CGI-S baseline score of $5.68(0.88)$ and an average BPRS score of 53.6 (11.6) indicating that these patients suffered from mild symptoms already at admission.

However, when we excluded Cluster 1, analyses indicated that Clusters 4 and 5 (employed inpatients) did not significantly differ on some demographic, anamnestic and network-related variables. Patients in Clusters 4 and 5 (employed patients) were the ones with more years of education and with less illness chronicity (shorter duration of illness and lower proportion of previous voluntary hospitalizations). They included patients with more limited use of mental health resources in last year yet with the higher adherence as compared with Clusters 2 and 3 (unemployed patients). The mean length of stay was compared between the different Clusters yet without finding a significant difference between them $(p=0.87)$ even if employed patients (Clusters 4 and 5) were found to have higher ordinary discharge. Moreover, as for the network size and the availability of a confident/supportive person, Clusters 4 and 5 (employed patients) were found to have the higher proportion of inpatients with a large network size.

However, we found some differences between Cluster 4 and 5. Cluster 5 (married and employed) was found to have a higher proportion of self-injuries at admission as compared with Clusters 1,2, with no differences as compared with Cluster 3 (married and unemployed) and 4 (unmarried and employed). Moreover, Cluster 5 included fewer patients with previous involuntary hospitalizations as compared with Cluster 3 and 4.

In the comparison between Clusters 2 and 3 (unemployed patients), Cluster 3 (the married ones) had a higher number of patients with Mania and a lower number of patients with Personality disorders. Also, the two patient Clusters appear to differ primarily on mean 
CGI-S and BPRS scores at admission, with patients in Cluster 3 (married unemployed) exhibiting a greater severity of symptoms.

Lastly, differences of substance abuse between Clusters have been found: married patients (Clusters 3 and 5) had lower frequencies of substance abuse.

\section{DISCUSSION}

This study provides information on pathways to care of specific patients' populations, promoting comparative research on the similarities and differences among inpatients admitted to PES in different countries.

Before commenting on our findings, we would like to point out two things. First, as regards real-world milestones achievement, the majority of the subjects were unemployed $(598 / 989,70.5 \%)$ : the bulk of the patients appears in Cluster 1, flanked by smaller but roughly equal numbers of patients in Clusters 2, 3, 4 . Second, people with Non Affective Psychoses comprise the $41.6 \%$ of patients with severe mental illnesses recruited in the present study.

Real-world milestone achievement can be rare in people with schizophrenia spectrum disorders and Harvey et al. (2012) have found that achievements of real-world milestones were very minimally related to each other and achievement of multiple current functional milestones across employment, residential independence, and social outcomes was very low at $6 \%$.

Although it is clear that many patients with severe mental illnesses do not work, the exact extent of the phenomenon is unclear, with studies reporting rates of full-time or part-time employment in patients with severe mental illnesses between $10 \%$ and $62 \%$ (Marwaha \& Johnson 2004, Marwaha et al. 2007, Kinoshita et al. 2013, Bell et al. 2014). A review of eight controlled trials has shown that the rates of unemployment for people with schizophrenia, even with optimal support, were reported to range from only $30 \%$ to $80 \%$, with a median of $60 \%$ across these studies (Bond 2004), even in the context that most people with severe mental illnesses consistently expressed their keenness to work (Ridgeway et al. 1992, Lehman 1995). These low employment rates reflect the disability caused by severe mental illness, but they may also reflect discrimination (unemployment rates are higher than in other disabled groups) (ONS 1998) and the low priority given to employment by psychiatric services (Lehman 1995). Mental health issues said to be linked to unemployment include: cognitive impairment, psychotic symptoms, negative symptoms, fear of losing benefits, stigma and lack of access to employment services (Rutman 1994, Cook 2006, Rosenheck et al. 2006, Bond \& Drake 2008). Moreover, it has been reported that unemployment among some of severely mental ill patients increased the number of frequent admissions of psychiatric patients to psychiatric hospitals (Haywood et al. 1995).
Thus, despite the five Clusters we found, one could argue that a solution with five groups is too complex, and that one should merge subgroups with parallel patterns as, for instance, the two groups of employed patients and unemployed ones. Moreover, GAF allowed us to split the unemployed and unmarried inpatients' subsample into two distinct clusters.

We will now highlight some of our most relevant findings.

\section{Employed inpatients}

The two groups of employed patients have quite similar characteristics. In many ways, patients in Cluster 4 (unmarried employed) were similar to patients in Cluster 5 (married employed) on the variables tabulated in Tables 1 and 2 as compared to patients in Clusters 2 and 3 (unemployed): they had more years of education, less illness chronicity (shorter duration of illness and lower proportion of previous voluntary hospitalizations), lower use of mental health resources in the last year yet higher treatment adherence, and larger network size. Interestingly, employed inpatients had a higher number of confident persons as compared to patients in Cluster 2 (unemployed and unmarried) but not as compared to patients in Cluster 3 (unemployed and married).

Unemployment undermines community integration and contributes to marginalization from mainstream society (Bartley 1994); leads to depression, increased institutionalization (Blustein 2008), decreased social support, community integration, social involvement, self-confidence and perceived recovery (Lloyd et al. 2010), placing additional stress on the psychological health of unemployed individuals (Ramsay et al. 2012, Bond et al. 2015).

Employment has been conceptualized as both an adverse health determinant (e.g., by causing stress and anxiety) and a positive health determinant (e.g., by encouraging self-esteem and offering numerous benefits, such as social identity and status, social contacts, and a means of structuring time), being a key factor in promoting the recovery process among individuals living with serious mental illnesses (Bush et al. 2009).

A recent review of longitudinal research on a total of 12 analyses including 6844 participants concluded that employment is more rehabilitative than a risky (Luciano et al. 2014). Achieving employment was associated with overall reductions in outpatient service use, reduced use of psychiatric treatment and increased self-esteem. However, employment was inconsistently associated with symptom severity, psychiatric hospitalization, life satisfaction, and global wellbeing.

Kukla and colleaugues (Kukla et al. 2012) outlined several possible explanations regarding the relationship between employment and outcomes. It may be that fewer symptoms made finding and maintaining work in time easier. Another possibility is that steady compe- 
titive work contributed to stable symptoms over time (and that the lack of work contributed to the maintenance of more severe symptoms over time) (Bond et al. 2001, Mueser et al. 1997). Thirdly, this relationship may be a feedback loop in which fewer symptoms make finding and keeping a job easier, and in turn, the process of working may then protect against worsening symptoms. Fourth, the features associated with noncompetitive jobs may allow for enhanced peer support and social integration (Barreira et al. 2010), a greater number of social contacts (Melle et al. 2000), increased opportunities to form friendships, less social disability (Burns et al. 2009) and enhanced patient competencies (Haro et al. 2006).

However, our findings suggest that social contact does not necessarily mean support. A person can have several friends and see them regularly but may not feel supported by any one of them or may consider only a few as really supportive (Magliano et al. 2006). A social network is a critical factor in reducing the detrimental effects of stress on individual psychological well-being (Cohen \& Syme 1985, Thoits 1995). It has been observed that social networks are the strongest factor in explaining adaptive coping towards problematic situations (Solomon \& Draine 1995). It has been also observed that the social tenure of patients with schizophrenia is significantly better among those who are in close contact with their families than among those living alone (Salokangas 1997, Warner et al. 1998). Furthermore, the network of a person with a severe mental disorder is more likely to include family members and more dependent relationships compared with the general population (Borge et al. 1999).

The capacity to work may reflect better social skills and resources and can also be a source of self-esteem and social support, factors that can contribute to a faster improvement (Gude \& Havik 2000). On the other hand, work dysfunction can be seen as a consequence of comorbidity and symptom severity. Moreover, persons with lower educational level and unemployed are reported to increase the risk of social isolation (Ross \& Van Willigen 1997, Cannuscio et al. 2004).

Lastly, employed patients were found to have higher ordinary discharge as compared to unemployed ones.

On the other hand, Cluster 5 included lower patients with previous involuntary hospitalizations as compared with the Cluster 3 (married and unemployed) and 4 (unmarried and employed).

\section{Married inpatients}

Marital status was not related to course or outcome, except as regards a lower percentage of substance abusers in Clusters 3 and 5 (married ones). This findings is consistent with the well-documented fact that unmarried status was significantly and positively associated with all types of dual diagnosis (Frieri et al. 2014, Cantor-Graae et al. 2001, Ponizovsky et al. 2015).
Indeed, it has been reported that the comorbidity with substance abuse is associated with a several negative effects on the family, including greater burden of care (Kashner et al.1991, Perlick et al. 2006) and family conflict, further straining family relationships (Dixon et al. 1995, Niv et al. 2007).

However, evidence is mixed regarding the "protective" role of marital status. Some studies have found that being married is usually associated with a better quality of life and protect against suicidal ideation in middle-aged and older individuals with schizophrenia or schizoaffective disorder and depressive symptoms, probably because having a partner is associated with less interpersonal problems (Wilberg et al. 1998), stronger social integration (Acock \& Hurlbert 1993) and increased social support (Sherbourne \& Hays 1990). On the other hand, other authors have found strong support that in cohabiting couples, partner's psychiatric morbidity associate with incidence of psychiatric disorders in healthy partners at baseline (Joutsenniemi et al. 2011) due to assortative mating (i.e. mate selection based on finding a mate that is phenotypically similar to oneself), secondary assortment (i.e. mate selection based on traits which correlate with psychiatric morbidity, such as age, education and employment status), and social homogamy (i.e. correlated geographic or social environments) (Eagles et al. 1987, Maes et al. 1998, Grant et al. 2007).

\section{Limits and strenghts}

The study had a number of limitations that should be highlighted. First, the cross-sectional design does not allow for causal inferences. Second, the measurement of social support may pose a problem in the validity of the result as it relied on self-report. However, the variables we employed did not involve a strong subjective evaluation by the participant. Third, it should be noted that cluster analysis is very exploratory in nature and the results are highly dependent on the selected variables. Fourth, the data come from a single PES in a single urban area. As a result, the results may not generalize to other service systems in other countries. Moreover, there may be limited applicability of these findings to inpatient populations in other locations, due to local differences in service provision, availability and clinical culture.

Despite these limitations, there are some points of strength of this study. The correlates included in the present study are restricted to the information available from standard medical records. On the other hand, using information based on ordinary clinical routines strengthens the external validity of the findings. Also adding to the strength of the study are the diagnostic assessments done by well-trained clinicians and the large sample size, making it possible to cross-validate the findings from the cluster analysis. Lastly, diagnostic assessments, correlating to DSM criteria were used for the diagnoses, rather than symptom checklist. 


\section{CONCLUSIONS}

To conclude: the present analysis of inpatient admission to a psychiatric ward during a 24-month period of inclusion identified five clusters, with different clinical and anamnestic characteristics. Although some of the findings might be related to the specific organization of Italian mental health services, therefore not universally applicable, our results provide a comprehensive picture of psychiatric admissions in the PES of the first hospital in Italy concerning the size and the indices for complexity of care, and may provide hints as how to best plan and use inpatient facilities for patients with severe mental illnesses; these findings can also be of use in order to plan similar studies in countries with different mental health care systems.

\section{Acknowledgements: None.}

\section{Conflict of interest: None to declare.}

\section{Contribution of individual authors:}

Cristiana Montemagni: conceptualized and designed the study, and drafted the manuscript;

Tiziana Frieri: collected the data and performed the statistical analysis;

Vincenzo Villari: conceptualized and designed the study, and contributed to the interpretation of analyzed data;

Paola Rocca: conceptualized and designed the study, collected the data, performed the statistical analysis and contributed to the interpretation of analyzed data.

\section{References}

1. Acock AC, Hurlbert JS: Social networks, marital status, and well-being. Social Networks 1993; 15:309-314

2. Alonso Suárez M, Bravo-Ortiz MF, Fernández-Liria A, González-Juárez C: Effectiveness of Continuity-of-Care Programs to reduce time in hospital in persons with schizophrenia. Epidemiol Psychiatr Sci. 2011; 20: 5-72

3. Altshuler LL, Gitlin MJ, Mintz J, Leight JL, Frye MA: Subsyndromal depression is associated with functional impairment in patients with bipolar disorder. J Clin Psychiatry 2002; 63:807-811

4. Barreira PJ, Tepper MC, Gold PB, Holley D, Macias C: Social value of supported employment for psychosocial program participants. Psychiatr Q 2010; 82: 69-84

5. Bartley M. Unemployment and ill health: understanding the relationship: J Epidemiol Community Health 1994; 48:333-337

6. Bell MD, Choi KH, Dyer C, Wexler BE: Benefits of cognitive remediation and supported employment for schizophrenia patients with poor community functioning. Psychiatr Serv 2014; 65:469-475

7. Bischof G, Rumpf HJ, Hapke U, Meyer C, John U: Types of natural recovery from alcohol dependence: a cluster analytic approach. Addiction 2003; 98:1737-1746
8. Blustein DL. The role of work in psychological health and wellbeing: a conceptual, historical, and public policy perspective. Am Psychol 2008; 630:228-240

9. Bond GR, Kim SJ, Becker DR, McEvoy J, Swartz M, Perkins D et al: A Controlled Trial of Supported Employment for People With Severe Mental Illness and Justice Involvement. Psychiatr Serv in Advance 2015; 66:1027-34

10. Bond GR, Drake RE: Predictors of competitive employment among patients with schizophrenia. Curr Opin Psychiatry 2008; 21:362-369

11. Bond GR: Supported employment: evidence for an evidence-based practice. Psychiatr Rehabil J 2004; 27:345-359

12. Bond GR, Resnick SG, Drake RE, Xie HY, McHugo GJ, Bebout RR: Does competitive employment improve nonvocational outcomes for people with severe mental illness? J Consult Clin Psychol 2001; 69: 489-501

13. Borge L, Martinsen EW, Torleif R, Watne O, Friis S: Quality of life loneliness and social contact among longterm psychiatric patients. Psychiatr Serv 1999; 50: 81-84

14. Bowers L: Reasons for admission and their implications for the nature of acute inpatient psychiatric nursing. $J$ Psychiatr Ment Health Nurs 2005; 12: 231-236

15. Burns T, Catty J, White S, Becker T, Koletsi M, Fioritti A, et al. EQOLISE Group: The impact of supported employment and working on clinical and social functioning: Results of an international study of Individual Placement and Support. Schizophr Bull 2009; 35:949-958

16. Bush PW, Drake RE, Xie H, McHugo GJ, Haslett WR: The long-term impact of employment on mental health service use and costs for persons with severe mental illness. Psychiatr Serv 2009; 60:1024-1031

17. Cannuscio CC, Colditz GA, Rimm EB, Berkman LF, Jones $C P$, Kawachi I: Employment status, social ties and caregivers' mental health. Soc Sci Med 2004; 58:1247-1256

18. Cantor-Graae E, Nordstrom LG, McNeil TF: Substance abuse in schizophrenia: A review of the literature and a study of correlates in Sweden. Schizophr Res 2001; 48:69-82

19. Chiu T, Fang D, Chen J, Wang Y, Jeris C: A robust and scalable clustering algorithm for mixed type attributes in large database environment. Proceedings of the 7th ACM SIGKDD International Conference on Knowledge Discovery and Data Mining, 263-268. ACM Press, San Francisco, 2001

20. Clatworthy J, Buick D, Hankins M, Weinman J, Horne R: The use and reporting of cluster analysis in health psychology: a review. Br J Health Psychol 2005; 10:329-358

21. Cohen S, Syme LS: Social support and health. Academic Press, Orlando, 1985

22. Cook JA: Employment barriers for persons with psychiatric disabilities: update of a report for the president's commission. Psychiatr Serv 2006; 57:1391-1405

23. Dixon LB, Schwarz EC: Fifty years of progress in community mental health in US: the growth of evidencebased practices. Epidemiol Psychiatr Sci 2014; 23:5-9

24. Dixon L, McNary S, Lehman A: Substance abuse and family relationships of persons with severe mental illness. Am J Psychiatry 1995; 152:456-458

25. Eagles JM, Walker LG, Blackwood GW, Beattie JA, Restall DB: The mental health of elderly couples. II. Concordance for psychiatric morbidity in spouses. $\mathrm{Br} J$ Psychiatry 1987; 150:303-308 
26. First MB, Gibbon M, Spitzer RL, Williams JBW, Benjamin LS: User's guide for the Structured Clinical Interview for DSM-IV Axis II Personality Disorders: SCID-II. American Psychiatric Press, Washington, DC, 1997 a

27. First MB, Spitzer RL, Williams JBW, Gibbon M: Structured Clinical Interview for DSM-IV Disorders (SCID). American Psychiatric Press, Washington, DC, $1997 \mathrm{~b}$

28. Frieri T, Montemagni C, Crivelli B, Scalese M, Villari V, Rocca P: Substance use disorders in hospitalized psychiatric patients: the experience of one psychiatric emergency service in Turin. Compr Psychiatry 2014; 55:1234-1243

29. Frieri T, Montemagni C, Rocca G, Rocca P, Villari V: Clinical outcome and length of stay in an Italian Psychiatric Emergency Service. Soc Psychiatry Psychiatr Epidemiol 2013; 48: 1013-1020

30. Grant JD, Heath AC, Bucholz KK, Madden PA, Agrawal A, Statham DJ, et al: Spousal concordance for alcohol dependence: evidence for assortative mating or spousal interaction effects? Alcohol Clin Exp Res 2007; 31: 717-728

31. Gude T, Havik OE: More than one way to change: a study of course heterogeneity during and after short-term psychiatric in-patient treatment. Scand J Psychol 2000; 41: $91-100$

32. Guy W. ECDEU: Assessment Manual for Psychopharmacology-Revised. Department of Health, Education and Welfare, Bethesda, 1976

33. Haro JM, Novick D, Suarez D, Alonso J, Lepine JP, Ratcliffe M: Remission and relapse in the outpatient care of schizophrenia: three-year results from the Schizophrenia Outpatient Health Outcomes study. J Clin Psychopharmacol 2006; 26: 571-578

34. Harvey PD, Sabbag S, Prestia D, Durand D, Twamley EW, Patterson TL: Functional milestones and clinician ratings of everyday functioning in people with schizophrenia: overlap between milestones and specificity of ratings. J Psychiatr Res 2012; 46: 1546-1552

35. Harvey PD, Raykov T, Twamley EW, Vella L, Heaton RK, Patterson TL: Validating the measurement of real-world functional outcomes: phase I results of the VALERO study. Am J Psychiatry 2011; 168: 1195-1201

36. Haywood TW, Kravitz HM, Grossman LS, Cavanaugh JL Jr, Davis JM, Lewis DA: Predicting the "revolving door" phenomenon among patients with schizophrenic, schizoaffective, and affective disorders. Am J Psychiatry 1995; 152: 856-861

37. Herman SE, Mowbray CT: Client typology based on functioning level assessments: utility for service planning and monitoring. $J$ Ment Health Adm 1991; 18:101-115

38. Jones SH, Thornicroft G, Coffey M, Dunn G: A brief mental health outcome scale-reliability and validity of the Global Assessment of Functioning (GAF). Br J Psychiatry. 1995; 166:654-659

39. Joutsenniemi K, Moustgaard H, Koskinen S, Ripatti S, Martikainen P: Psychiatric comorbidity in couples: a longitudinal study of 202,959 married and cohabiting individuals Soc Psychiatry Psychiatr Epidemiol 2011, 46:623-633

40. Kashner M, Rader L, Rodell D, Beck C, Rodell L, Muller K: Family characteristics, substance abuse, and hospitalization patterns of patients with schizophrenia. Hosp Community Psychiatry 1991; 42: 195-197

41. Kinoshita Y, Furukawa TA, Kinoshita K, Honyashiki M, Omori IM, Marshall M et al: Supported employment for adults with severe mental illness. Cochrane Database Syst Rev 2013; 9: CD008297

42. Kukla M, Bond GR, Xie H: A Prospective Investigation of Work and Nonvocational Outcomes in Adults With Severe Mental Illness. J Nerv Ment Dis 2012; 200: 214-222

43. Lehman AF: Vocational rehabilitation in schizophrenia Schizophr Bull 1995; 21: 645-656

44. Leung WW, Bowie CR, Harvey PD: Functional implications of neuropsychological normality and symptom remission in older outpatients diagnosed with schizophrenia: A crosssectional study. J Int Neuropsychol Soc 2008; 14:479-488

45. Lloyd C, King R, Moore L: Subjective and objective indicators of recovery in severe mental illness: a crosssectional study. Int J Soc Psychiatry 2010; 56: 220-229

46. Luciano A, Bond GR, Robert E, Drake RE: Does employment alter the course and outcome of schizophrenia and other severe mental illnesses? A systematic review of longitudinal research. Schizophr Res 2014; 159: 312-321.

47. Lysaker PH, Davis LW, Tsai J: Suspiciousness and low self-esteem as predictors of misattributions of anger in schizophrenia spectrum disorders. Psychiatry Res 2009; 166: 125-131

48. Maes HH, Neale MC, Kendler KS, Hewitt JK, Silberg JL, Foley DL et al: Assortative mating for major psychiatric diagnoses in two population-based samples. Psychol Med 1998; 28: 1389-1401

49. Magliano L, Fiorillo A, Malangone C, De Rosa C, Maj M, National Mental Health Project Working Group: Social network in long-term diseases: A comparative study in relatives of persons with schizophrenia and physical illnesses versus a sample from the general population. Soc Sci Med. 2006; 62: 1392-1402

50. Martinez-Aran A, Vieta E, Torrent C, Sanchez-Moreno J, Goikolea JM, Salamero M: Functional outcome in bipolar disorder: the role of clinical and cognitive factors. Bipolar Disord. 2007; 9: 103-113

51. Martinez-Aran A, Vieta E, Colom F, Torrent C, SánchezMoreno J, Reinares M: Cognitive impairment in euthymic bipolar patients: implications for clinical and functional outcome. Bipolar Disord 2004; 6: 224-232

52. Marwaha $S$, Johnson $S$, Bebbington $P$ Stafford $M$, Angermeyer MC, Brugha $T$ et al: Rates and correlates of employment in people with schizophrenia in the UK, France and Germany. Br J Psychiatry 2007; 191: 30-37

53. Marwaha S, Johnson S: Schizophrenia and employment a review. Soc Psychiatry Psychiatr Epidemiol 2004; 39:337-349

54. Melle I, Friis S, Hauff E, Vaglum P: Social functioning of patients with schizophrenia in high-income welfare societies. Psychiatr Serv 2000; 51: 223-228

55. Miller GA, Chapman JP: Misunderstanding analysis of covariance. J Abnorm Psychol 2001; 110: 40-48

56. Montemagni C, Frieri T, Villari V, Rocca P: Compulsory admissions of emergency psychiatric inpatients in Turin: the role of diagnosis. Prog Neuropsychopharmacol Biol Psychiatry 2012; 39: 288-294

57. Mueser KT, Becker DR, Torrey WC, Xie H, Bond GR, Drake RE et al: Work and nonvocational domains of functioning in persons with severe mental illness: A longitudinal analysis. J Nerv Ment Dis 1997; 185: 419-426

58. Murphy S, Irving CB, Adams CA, Driver R: Crisis Intervention for People With Severe Mental Illnesses. Schizophr Bull 2012; 38: 676-677 
59. Niv N, Lopez SR, Glynn SM, Mueser KT: The role of substance use in families, attributions and affective reactions to their relative with severe mental illness. $J$ Nerv Ment Dis 2007; 195:307-314

60. ONS: Labour force survey (1997/1998). Office of National Statistics: London, 1998

61. Overall JE, Gorham DR: The Brief Psychiatric Rating Scale. Psychological Reports 1962; 10:799

62. Perlick DA, Rosenheck RA, Kaczynski R, Swartz MS, Cañive JM, Lieberman JA: Components and correlates of family burden in schizophrenia. Psychiatr Serv 2006; 57:1117-1125

63. Ponizovsky AM, Rosca P, Haklai Z, Goldberger N: Trends in dual diagnosis of severe mental illness and substance usedisorders, 1996-2010, Israel. Drug Alcohol Depend $2015 ; 148: 203-208$

64. Ramsay CE, Stewart T, Compton MT: Unemployment among patients with newly diagnosed first-episode psychosis: prevalence and clinical correlates in a US sample. Soc Psychiatry Psychiatr Epidemiol 2012; 47:797-803

65. Ridgeway P, Rapp C, Hatfield B, Huxley P, Mohamad H: Accommodation and employment: a survey into the circumstances and expressed needs of users of mental health services in a northern town. Br J Soc Work 1992; 22:61-73

66. Rosenheck R, Leslie D, Keefe R McEvoy J, Swartz M, Perkins D et al: CATIE Study Investigators Group: Barriers to employment for people with schizophrenia. Am J Psychiatry 2006; 163: 411-417

67. Ross CE, Van Willigen M: Education and the subjective quality of life. J Health Soc Behav 1997; 38:275-297
68. Rutman ID: How psychiatric disability expresses itself as a barrier to employment. Psychosocial Rehabilitation Journal 1994; 17: 15-35

69. Salokangas RK: Living situation, social network and outcome in schizophrenia: A five-year prospective followup study. Acta Psychiatr Scand 1997; 96: 459-468

70. Santone G, Rucci P, Muratori ML, Monaci A, Ciarafoni C, Borsetti G: Attitudes toward medication in inpatients with schizophrenia: a cluster analytic approach. Psychiatry Res 2008; 158:324-334

71. Sherbourne CD, Hays RD: Marital status, social support, and health transitions in chronic disease patients. $J$ Health Soc Behav 1990; 31:328-343

72. Solomon P, Draine J: Adaptive coping among family members of persons with serious mental illness. Psychiatr Serv 1995; 46: 1156-1160

73. Theodoritis S, Koutrumbas K: Pattern Recognition. Academic Press, New York, 1999

74. Thoits PA: Stress, coping, and social support processes: Where are we? What next? J Health Soc Behav 1995; 53-79

75. Unick GJ, Kessell E, Woodard EK, Leary M, Dilley JW, Shumway M: Factors affecting psychiatric inpatient hospitalization from a psychiatric emergency service. Gen Hosp Psychiatry 2011; 33:618-625

76. Warner R, de Girolamo G, Belelli G, Bologna C, Fioritti $A$, Rosini $G$ : The quality of life of people with schizophrenia in Boulder, Colorado, and Bologna, Italy. Schizophr Bull 1998; 24:559-568

77. Wilberg T, Friis S, Karterud S, Mehlum L, Urnes O, Vaglum P: Patterns of short-term course in patients treated in a day unit for personality disorders. Compr Psychiatry 1998; 39:75-84

Correspondence:

Paola Rocca, MD

Department of Neuroscience, Psychiatric Section, University of Turin

Via Cherasco 11, 10126 Turin, Italy

E-mail:paola.rocca@unito.it 